\title{
Risk-Type Concentration and Efficiency Incentives: A Challenge for the Risk Adjustment Formula*
}

\author{
Richard C. van Kleef ${ }^{\mathrm{a}}$, Konstantin Beck ${ }^{\mathrm{b}, \mathrm{c}}$ and Florian Buchner ${ }^{\mathrm{d}}$ \\ ${ }^{a}$ Institute of Health Policy and Management, Erasmus University Rotterdam, P.O. Box 1738, \\ 3000 DR Rotterdam, the Netherlands. \\ ${ }^{\mathrm{b}}$ Socioeconomic Institute, University of Zurich, Hottingerstrasse 10, CH-8032 Zurich, Switzerland. \\ ${ }^{\mathrm{c}}$ CSS Institute for Empirical Health Economics, Tribschenstrasse 21, CH-6002 Lucerne, Switzerland. \\ E-mail: konstantin.beck@css.ch \\ ${ }^{\mathrm{d}}$ Department of Health, Carinthia University of Applied Sciences, Primoschgasse 10, 9020 Klagenfurt, \\ Austria. \\ E-mail: F.Buchner@fh-kaernten.at
}

An important goal of risk-adjusted capitation payments (RACPs) to competitive communityrated health plans - that may differ in coverage and/or the organisation of delivering careis to reduce incentives for risk selection while maintaining incentives for efficiency. In most schemes, RACPs are simply based on the average observed costs in risk groups (in a prior year). We show that under this procedure, incentives for efficiency will not always be maintained: when identical risk types are concentrated in the same health plans - due to selection, specialisation or just coincidence - cost savings can be captured by the RACPs and leak away from these plans.

The Geneva Papers (2010) 35, 503-520. doi:10.1057/gpp.2010.25

Keywords: health insurance; capitation payments; risk adjustment; efficiency

\section{Introduction}

In more and more social health insurance schemes around the world, managed competition is applied to combine the efficiency advantages of a competitive market with some level of cross-subsidisation from low-risk enrollees (e.g. the young and healthy) to high-risk enrollees (e.g. the elderly and chronically ill). ${ }^{1}$ With competitive we mean that consumers can periodically switch among insurance plans - that may differ in coverage and/or the organisation of care - offered by risk-bearing insurers. Social health insurance means that some form of community-rating is established: premiums or contribution rates may vary among health plans but not within health plans, that is health plans are not allowed to differentiate their premium, respectively, their contribution rate according to the risk characteristics of individuals. In most of these schemes, community-rating is supplemented by a system of risk-adjusted capitation payments (RACPs). This system provides health plans with an amount of

\footnotetext{
* The authors gratefully acknowledge two anonymous reviewers and the members of the Risk Adjustment Network (RAN) for their valuable comments on earlier versions of this paper. Remaining errors are ours.

${ }^{1}$ For the principles of managed competition we refer to Enthoven (1978).
} 
money for each enrollee on their list, adjusted for risk characteristics such as age, gender and health status. ${ }^{2}$

Given the requirement of community-rating, the goal of RACPs is to reduce incentives for risk selection while maintaining incentives for efficiency in production. ${ }^{3}$ As defined by Newhouse, "risk selection" includes actions of consumers and health plans to exploit unpriced risk heterogeneity and break pooling arrangements, and efficiency in production" (further: efficiency) means choosing the least costly treatment for a patient's medical problem, holding quality constant.

Schokkaert and Van de Voorde ${ }^{5}$ argue that two important choices have to be made with respect to the risk adjustment formula (i.e. the formula according to which RACPs are calculated). In the first place, the regulator has to decide for which risk factors compensation is desired. Common risk factors in capitation schemes are age, gender and health status. In the second place, the regulator has to choose the weights for (the risk groups deduced from) these risk factors. In most capitation schemes, these weights are simply based on the average observed costs in risk groups (in a prior year). This procedure has been criticised in the literature from different perspectives. Glazer and McGuire ${ }^{6}$ and Jack $^{7}$ argue that when risk adjusters are only imperfect signals of an individual's risk profile, the RACP for the high risks (those with the bad signal, e.g. the elderly) should exceed their expected costs, while the opposite holds for the low risks (those with the good signal, e.g. the young). Schokkaert et al. ${ }^{8}$ reveal an inevitable trade-off between risk selection and efficiency when the risk adjustment formula is not additively separable in risk factors for which compensation is desired (i.e. C-variables) and risk factors for which compensation is not desired (i.e. R-variables).

The goal of this paper is to illustrate another problem when simply basing RACPs on the average observed costs in risk groups: when identical risk types are concentrated in the same health plans - for example due to selection, specialisation or just coincidencecost savings can be (partly) captured by the RACPs and leak away from these plans. For example, when RACPs are based on the average observed costs in risk groups "old" and "young" and all the young are enrolled in an efficiently managed care plan while all the old are enrolled in an inefficient traditional plan, the RACPs will compensate for the entire cost difference between the two groups including the cost savings in the managed care plan. When the two plans learn about the outcome of the risk adjustment formula, they have no incentive to (further) reduce their costs. In this extreme case, the capitation system in fact functions as a cost-reimbursement system. ${ }^{9}$

\footnotetext{
${ }^{2}$ Van de Ven et al. (2003).

${ }^{3}$ Without a requirement of community-rating the goal of RACPs can be to make insurance plans affordable for high-risk enrollees (e.g. Eekhoff et al., 2006).

${ }^{4}$ Newhouse (1996a).

${ }^{5}$ Schokkaert and Van de Voorde (2004).

${ }^{6}$ Glazer and McGuire (2000).

${ }^{7}$ Jack (2006).

${ }^{8}$ Schokkaert et al. (1998).

${ }^{9}$ With cost reimbursement we mean that health plans are reimbursed for their actual costs.
} 
When the efficiency of health plans is considered as an R-variable and age is considered as a C-variable, this problem fits in the framework of Schokkaert et al. ${ }^{10}$ : concentration of the young in efficient health plans (and concentration of the old in inefficient health plans) implies that (pure) age-related cost differences and efficiencyrelated cost differences are not additively separable. When RACPs are simply based on the average observed costs in age groups they will capture (a part) of the cost savings in the efficient plans. Consequently, the RACP will be "too high" for the old and "too low" for the young. So, cost savings are eaten up by the RACPs, thereby destroying the incentives for efficiency. Hence, we will illustrate the implications.

The structure of this paper is as follows. Section "An empirical example" starts with an empirical illustration based on administrative data from a Swiss insurer. Section "A general framework" formulates the general conditions under which cost savings will be captured by the RACPs and the section on "Real-world examples: deductibles and managed care" provides an overview of real-world situations in which this will happen. Section "How to avoid that RACPs capture cost savings" discusses two measures to prevent RACPs from capturing cost savings. The last section summarises the main conclusions.

\section{An empirical example}

We assume that incentives for efficiency are maintained when in the presence of RACPs health plans. They have the same incentives for efficiency as in the absence of RACPs. This implies that RACPs must not violate the following condition: $x$ euro average cost savings in plan $B$ compared to plan $A$ should enable plan $B$ to reduce the premium by $x$ euro compared to plan $A$. Violation of this condition can be illustrated with empirical data from a Swiss insurer including individual-level information on reimbursed health care costs, deductible choice and age in the year 2003. In that year, Swiss residents - who are obliged to obtain basic health insurance since 1996- had a mandatory deductible of CHF230, which could be voluntarily increased to a maximum of $\mathrm{CHF} 1,500 .{ }^{11}$ In the data, 17,829 individuals had chosen the highest deductible and 71,864 individuals had chosen no voluntary deductible. ${ }^{12}$ Van Kleef et $a l .{ }^{13}$ have found that the average cost savings in the high-deductible plan were CHF 750 per person (not including the self-selection effect). ${ }^{14}$ Since the data in our illustration are exactly the same as those used by Van Kleef et al. (ibid.), we use their estimation results and refer to their study for the method and its validity. ${ }^{15}$

${ }^{10}$ Schokkaert et al. (1998).

${ }^{11} \mathrm{CHF} 1=€ 0.61 / \mathrm{US} \$ 0.90$, on 1 January 2008.

${ }^{12}$ For a description of the Swiss scheme we refer to Beck et al. (2003) and for a description of the data we refer to Van Kleef et al. (2008).

${ }^{13}$ Van Kleef et al. (2008).

${ }^{14}$ From the health plan's perspective, cost savings in the deductible plan has two components: increased out-of-pocket expenditures and a moral hazard reduction.

${ }^{15}$ In sum, a four-step estimation procedure was used to estimate the out-of-pocket expenditures and the moral hazard reduction: (1) estimate an expenditure model on the group of insured without a voluntary deductible; (2) predict expenses of the insured with a voluntary deductible by combining their 
Table 1 Distribution of individuals over health plans and risk types

\begin{tabular}{|c|c|c|c|}
\hline & Standard plan & Deductible plan & Total \\
\hline \multirow{2}{*}{ Young } & 31,162 & 13,624 & 44,786 \\
\hline & $(35 \%)$ & $(15 \%)$ & $(50 \%)$ \\
\hline \multirow[t]{2}{*}{ Old } & 40,702 & 4,205 & 44,907 \\
\hline & $(45 \%)$ & $(5 \%)$ & $(50 \%)$ \\
\hline \multirow[t]{2}{*}{ Total } & 71,864 & 17,829 & 89,693 \\
\hline & $(80 \%)$ & $(20 \%)$ & $(100 \%)$ \\
\hline
\end{tabular}

By applying a simplified risk adjustment formula we will show that the voluntarydeductible plan will not be able to reduce its premium by CHF750 compared to the standard plan.

Let us assume that RACPs are calculated according to formula (1), with $C_{j}$ as the average observed costs in risk group $j$ and $C$ as the average observed costs in the population.

$$
R A C P_{j}=C_{j}-C
$$

Differences in RACPs between risk groups reflect differences in average observed costs between these risk groups, which is in principle the case in Switzerland, The Netherlands and Germany, for instance. ${ }^{16}$ In this example, only two risk types are distinguished: the young $(j=Y)$ and the old $(j=\mathrm{O})$, each representing 50 per cent of the population.

Table 1 shows how the young and the old are actually distributed over the two health plans. It appears that the share of young people having the deductible plan is higher than the share of old people having the deductible plan. This may be a result of adverse selection in a way that low-risk individuals (the young) are more likely to choose a deductible than high-risk individuals (the old).

Table 2 shows the average cost savings per risk type in the voluntary-deductible plan compared to the standard plan. Obviously, the average cost savings are higher for the old than for the young. As explained by Van Kleef et al., ${ }^{12}$ this is caused by the fact that the average (expected) expenses of individuals in the voluntary-deductible plan are higher for the old people than for the young people. These above-average expenses for the old result in above-average, out-of-pocket expenses and above-average moral hazard reduction (holding price-sensitivity constant).

characteristics with the coefficients obtained in the first step; (3) estimate expected out-of-pocket expenditures using the results of the second step; (4) estimate moral hazard reduction due to deductible $d$ as the expected expenses for insured with deductible $d$ minus the medical expenses paid by the insurer and minus their expected out-of-pocket expenditures. In their estimation procedure, the authors explicitly correct for the potential endogeneity caused by self-selection.

${ }^{16}$ For details about the principles of RACPs to health plans we refer to Van de Ven and Ellis (2000) and for details about the specific capitation schemes in Switzerland, the Netherlands and Germany we refer to Beck et al. (2003), Lamers et al. (2003), Buchner and Wasem (2003), Van de Ven et al. (2003) and Van de Ven et al. (2007). 
Table 2 Average cost savings in $\mathrm{CHF}^{\mathrm{a}}$

\begin{tabular}{lcr}
\hline & Standard plan & Deductible plan \\
\hline Young & 0 & 642 \\
Old & 0 & 1,096 \\
Mean & 0 & 749 \\
\hline
\end{tabular}

${ }^{a}$ The overall average cost savings are slightly different from the CHF750 mentioned earlier due to rounding.

Table 3 Effect of cost savings on the average costs in $\mathrm{CHF}$

\begin{tabular}{|c|c|c|c|}
\hline & Standard plan & Deductible plan & Total \\
\hline Young & 0 & -642 & -195 \\
\hline Old & 0 & $-1,096$ & -103 \\
\hline Total & 0 & -749 & -149 \\
\hline
\end{tabular}

Table 4 Effect of cost savings on RACPs in CHF

\begin{tabular}{lllr}
\hline & $\begin{array}{l}\text { RACP without } \\
\text { cost savings }\end{array}$ & $\begin{array}{l}\text { RACP with } \\
\text { cost savings }\end{array}$ & Change in RACP \\
\hline Young & $C_{Y}-C$ & $\left(C_{Y}-195\right)-(C-149)$ & -46 \\
Old & $C_{O^{-}}$ & $\left(C_{O}-103\right)-(C-149)$ & 46 \\
\hline
\end{tabular}

Let us assume that in a situation without deductibles the capitation payment for the young would be $R A C P_{Y}$ and the capitation payment for the old would be $R A C P_{O}$. The main point of this paper is as follows: if RACPs are calculated according to formula (1) the occurrence of the cost savings in Table 2 influences the RACPs in a way that the average cost savings of CHF749 cannot fully return in the premium reduction for the voluntary-deductible plan (compared to the standard plan). How does this exactly work? Using the number of enrollees per cell in Table 1, it can be calculated that the cost savings in Table 2 lead to a decrease in the average costs of CHF195 for the young, CHF103 for the old and CHF149 for the entire population, as summarised in Table 3.

As summarised in Table 4, the reduction in average costs results in a change of RACPs. The explanation is as follows: average costs for the young decrease by CHF195 (i.e. $\left.C_{Y}-195\right)$ while the average costs in the total population decrease by (only) CHF149 (i.e. $C-149$ ). Following formula (1), this results in a reduction of $R A C P_{Y}$ by CHF46. For the old, the average costs decrease by CHF103 (i.e. $C_{O}-103$ ), which implies an increase in $\mathrm{RACP}_{\mathrm{O}}$ by $\mathrm{CHF} 46$.

From the health plans' perspective the net effect of cost savings equals the average cost savings minus the change in RACP. For our empirical example the net effects are shown in Table 5. Under community-rated premiums per health plan, these net effects allow the deductible plan to reduce its premium by CHF725 and allow the standard plan to reduce its premium by $\mathrm{CHF}$. The resulting premium difference between the two plans (CHF719) is lower than the average cost savings of CHF749 (Table 2). This means that 4 per cent of the cost savings in the deductible plan leak away through the 
Table 5 Net effect of cost savings on the average costs and community-rated premiums in CHF

\begin{tabular}{lrr}
\hline & Standard plan & Deductible plan \\
\hline Young & 46 & -596 \\
Old & -46 & $-1,142$ \\
Change in community-rated premium & -6 & -725 \\
\hline
\end{tabular}

Table 6 Distribution of risk types over health plans

\begin{tabular}{lll}
\hline & Plan $A$ & Plan B \\
\hline Low risks & $1-h_{L}$ & $h_{L}$ \\
High risks & $1-h_{H}$ & $h_{H}$ \\
\hline
\end{tabular}

RACPs and only 96 per cent can actually return in a premium reduction compared to the standard plan. ${ }^{17}$

Analogous to the procedure used above, we calculated that under the actual risk classes for age and gender in the Swiss capitation scheme of 2008, 6 per cent of the cost savings in the voluntary-deductible plan leak away through the RACPs. Appendix A shows the change in RACP for the 26 age/gender-classes due to the (estimated) cost savings in the voluntary-deductible plan.

\section{A general framework}

A close look at the empirical example reveals that whether or not cost savings are captured by RACPs and leak away from health plans depends on two parameters: (1) the level of concentration of identical risk types in the same health plans; and, (2) the relationship between cost savings and risk types. Let us transform the empirical illustration into a more general framework: we refer to the inefficient plan as A and to the efficient plan as B (which can be a deductible plan, managed care plan or anything alike). We define $h_{L}$ as the share of low risks in plan $B$ and $h_{H}$ as the share of high risks in plan B. Table 6 shows the distribution of risk types over health plans.

In addition, we define $S^{B}$ as the overall average cost savings in plan B, $S_{L}^{B}$ as the average cost savings for low risks with plan B and $S_{H}^{B}$ as the average cost savings for high risks with plan $\mathrm{B}$.

Appendix B shows the premium reduction for plan B in relation to the average cost savings in plan B under different assumptions about the shares of low risks and high risks in plan $\mathrm{B}$ and the relation between cost savings and risk type. This exercise reveals five different scenarios, which are summarised in Table 7 .

${ }^{17}$ Using the numbers of enrollees from Table 1, the change in community-rated premium for the standard plan can be calculated as $(31,162 \times \mathrm{CHF} 46+40,702 \times \mathrm{CHF}-46) / 71,864$. The change in communityrated premium for the deductible plan can be calculated as $(13,624 \times \mathrm{CHF}-596+4,205 \times \mathrm{CHF}-1,142) /$ 17,829 . 
Table 7 Five relevant scenarios

\begin{tabular}{llll}
\hline & $\begin{array}{l}\text { Level at which identical } \\
\text { risk types are concentrated } \\
\text { in the same health plans }\end{array}$ & $\begin{array}{l}\text { Relation between risk } \\
\text { type and cost savings }\end{array}$ & $\begin{array}{l}\text { Premium reduction as a } \\
\text { percentage } p \text { of the } \\
\text { average cost savings }\end{array}$ \\
\hline I & Full concentration $\left|h_{L}-h_{H}\right|=1$ & Any & $p=0$ \\
II & No concentration $\left|h_{L}-h_{H}\right|=0$ & Any & $p=100$ \\
III & Some concentration $0<\left|h_{L}-h_{H}\right|<1$ & $S_{H}^{B}=\frac{h_{L}}{h_{H}} S_{L}^{B}$ & $p=100$ \\
IV & Some concentration $0<\left|h_{L}-h_{H}\right|<1$ & $S_{H}^{B}<\frac{h_{L}}{h_{H}} S_{L}^{B}$ & $0<p<100$ \\
V & Some concentration $0<\left|h_{L}-h_{H}\right|<1$ & $S_{H}^{B}>\frac{h_{L}}{h_{H}} S_{L}^{B}$ & $p>100$ \\
\hline
\end{tabular}

The precise level of $p$ in scenarios IV and $\mathrm{V}$ depends on the relative size of risk groups $\mathrm{L}$ and $\mathrm{H}$. Appendix $\mathrm{C}$ presents the level of $p$ for a situation where $\mathrm{L}$ and $\mathrm{H}$ have exactly the same size (like in our empirical example).

\section{Scenario I}

If all the low risks have plan B and all the high risks have plan A (or vice versa), the cost savings $S^{B}$ cannot at all be incorporated into the premium reduction for plan $\mathrm{B}$. The simple explanation is that payments $R A C P_{L}$ and $R A C P_{H}$ (computed according to formula (1)) capture all cost differences between the two groups, including the cost savings in plan B.

\section{Scenario II}

If the share of low risks having plan $\mathrm{A}$ and the share of high risks having plan $\mathrm{B}$ are equal, the cost savings can be fully incorporated into the premium reduction for plan B. Note that RACPs are influenced by cost savings in plan B when these are different for the two risk groups (e.g. average cost savings are higher for the low risks than for the high risks). The resulting over-compensations (for the low risks) and under-compensations (for the high risks), however, have no effect on the premium reduction since the risk composition of the two plans is identical. More specifically, the total over-compensation (for the low risks) and under-compensation (for the high risks) is equal in both plans, such that the net effect of RACPs on the premium reduction is zero.

\section{Scenario III}

In practice, the level of concentration probably lays in between the extremes of scenarios I and II. If this is the case, then only in one exceptional situation the premium reduction will equal the average cost savings: when the average cost savings in the (entire) risk groups is exactly the same, that is $S_{H}=S_{L}$. In the terminology of Tables 6 and 8 this can be written as: $S_{H}^{B}=\frac{h_{L}}{h_{H}} S_{L}^{B}$. For instance, if 50 per cent of the low risks have plan $\mathrm{B}$ and 25 per cent of the high risks have plan B then no cost savings are captured by the RACPs if $S_{H}^{B}$ is $0.50 / 0.25$ times $S_{L}^{B}$. 
Table 8 Distribution of average cost savings over health plans and risk types

\begin{tabular}{lcc}
\hline & Plan $A$ & Plan B \\
\hline Low risks & 0 & $S_{L}^{B}$ \\
High risks & 0 & $S_{H}^{B}$ \\
Mean & 0 & $S^{B}$
\end{tabular}

\section{Scenario IV}

Also in the fourth scenario identical risk types are to some extent concentrated in the same health plans, but $S_{H}^{B}<\frac{h_{L}}{h_{H}} S_{L}^{B}$. This is exactly the case in our empirical illustration: the share of individuals having the voluntary-deductible plan equals 0.30 for the young and 0.09 for the old, while the average cost savings for the old with that plan (i.e. $€ 1,096$ ) are lower than $0.30 / 0.09$ times the average cost savings for the young with that plan (i.e. $€ 642$ ). In this scenario RACPs will (partially) capture cost savings in plan B, which can therefore not fully return in the premium reduction compared to plan A.

\section{Scenario $V$}

Also in the last scenario identical risk types are to some extent concentrated in the same health plans, but $S_{H}^{B}>\frac{h_{L}}{h_{H}} S_{L}^{B}$. Under these conditions the premium reduction for plan B can exceed the average cost savings in plan B. In our empirical example this would have been the case when the average cost savings of high risks in plan B exceeded $€ 2,086$ (i.e. $\frac{0.30}{0.09} \times € 642$ ).

\section{Real-world examples: deductibles and managed care}

What can we learn from the previous exhibition? Hence, we will show the relevance of our framework for two common types of cost-containing health plans in practice: voluntary-deductible plans and managed-care plans. The questions to be answered are: "Will cost savings be (partially) captured by the RACPs?" and if yes "What will be the policy implications?".

\section{Cost savings on the demand side: voluntary-deductible plans}

In practice, it is evident that low risks have a stronger preference for deductible plans than high risks. ${ }^{12,18,19,20,21}$ The resulting concentration of identical risk types in the same health plans has serious implications: with a sophisticated set of risk adjusters the

18 Bakker et al. (2000).

19 Schellhorn (2001).

${ }^{20}$ Gardiol et al. (2006).

${ }^{21}$ For other evidence on (adverse) selection we refer to Browne (1992), Beck (2004), Buchmueller (2008) and Van de Ven and Van Vliet (1994). 
capitation system might reduce the premium reduction such that deductible plans will hardly be attractive to consumers, not even for the healthiest individuals in the population. The explanation is as follows. Bakker et al. (ibid.) have shown that the premium reduction for deductible plans compared to no-deductible plans can roughly consist of three components: the out-of-pocket expenses by enrollees, the moral hazard reduction and the effect of selection (i.e. health-related cost differences between individuals who prefer a deductible and those who do not). As better risk adjusters are taken into account in the risk adjustment formula, the effect of self-selection will be smaller since RACPs will compensate for health-related cost differences between enrollees with a deductible and enrollees without a deductible, which is in fact an important goal of RACPs. However, when RACPs are based on the (average) observed insurance claims - as is currently the case in most health insurance schemes - not just the self-selection effect will be compensated for but also the real-cost savings (i.e. the out-of-pocket expenses and moral hazard reduction). Thus, if the risk adjustment formula includes a sophisticated set of risk adjusters, the premium reduction for deductible plans may be lower than the average cost savings. Consequently, deductible plans might be hardly attractive - particularly for high risks who expect their out-of-pocket expenses to exceed the premium reduction - which makes deductible plans a less effective instrument to reduce moral hazard.

Given that low risks tend to concentrate in deductible plans, we expect to end up in scenario IV (as in our empirical illustration). Occurrence of scenario III or V is unlikely since it requires that average cost savings in a deductible plan are much higher for high risks than for low risks. High-cost savings (i.e. out-of-pocket expenses and moral hazard reduction) require substantial (expected) expenses, which are exactly the reason for not choosing a deductible plan.

\section{Cost savings on the supply side: managed care}

Our framework is also relevant for cost savings on the supply side of health care, for example cost savings due to managed care. Concentration of identical risk types in the same health plans can occur for different reasons. For example, health plans specialised in managing the care for diabetes might attract relatively many diabetes patients. When diabetes is included as a risk adjuster in the risk adjustment formulafor example in the form of a pharmacy cost group or diagnostic cost group ${ }^{22}$ - the RACPs will not just correct for health-related expenditure differences between health plans but also for the cost savings in the specific diabetes plans. A second example is health plans specialised in managing the care in specific geographical regions which attract relatively many consumers in these regions. If a region is included as a risk adjuster in the risk adjustment formula, the RACPs will not just compensate for health-related cost differences between regions but also level out cost savings achieved in geographical plans. A third example is health plans specialised in managing the care for the elderly which attract a relative amount of older consumers. In general terms, the argument is the same as above: if age is included as a risk adjuster in the risk

\footnotetext{
${ }^{22}$ Lamers (1998), Lamers (1999).
} 
adjustment formula, the RACPs will not just compensate for health-related cost differences between age groups, but also for the cost savings achieved in age-specific health plans. When health plan executors learn about this, the financial incentives for efficiency diminish compared to a situation without risk-adjusted capitation payments.

In the previous examples, we expect to end up in scenario IV (i.e. premium rebate $<$ average cost savings). Occurrence of scenario III (i.e. premium rebate $=$ average cost savings) or $\mathrm{V}$ (i.e. premium rebate $>$ average cost savings) is unlikely since it requires that average cost savings in a managed care plan are much higher for risk types that are underrepresented in the plan than for risk types that are concentrated in the plan. Exactly the opposite is expected to happen: average cost savings are likely to be higher for risk types in which plans are specialised. ${ }^{23}$

\section{How to avoid that RACPs capture cost savings}

In theory, two alternative ways of calculating RACPs can avoid that RACPs capture cost savings. The first is basing RACPs on the average observed costs within health plans, as summarised in formula (2), with $C_{j}^{p}$ as the average observed costs of risk group $j$ in plan $p$ and $C^{p}$ as the average observed costs in plan $p$.

$$
R A C P_{j}^{p}=C_{j}^{p}-C^{p} .
$$

This alternative is a feature of the payment scheme proposed by Barros. ${ }^{24}$ When RACPs are based on observed cost differences within health plans, then cost differences between health plans will not affect RACPs. As a result, plan-related cost savings stay with health plans and can be fully incorporated into premiums. From a practical point of view, however, this alternative has two serious drawbacks. In the first place, the condition of horizontal equity, as defined by Schokkaert and Van de Voorde, ${ }^{5}$ will be violated in the sense that RACPs can differ for the same risk types in different plans. In the second place, the number of individuals per cell (i.e. health plan/risk group) might be too low to ensure that the average observed costs in a risk group is a valid estimation of the expected expenses.

The second alternative is to correct the observed costs for cost savings before RACPs are calculated, as summarised in formula (3) with $S_{j}$ as the average cost savings in risk group $j$ and $S$ the average cost savings in the population.

$$
R A C P_{j}=\left(C_{j}+S_{j}\right)-(C+S) .
$$

${ }^{23}$ It should be mentioned that, in practice, occurrence of scenario III or V is not impossible. An example, comes from the Swiss basic health insurance where managed care plans have contracted relatively many young consumers (due to selection): it might be possible that the average cost savings in these plans are much higher for the (minority of) old enrollees than for the (majority of) young enrollees. If average cost savings for the old are a factor $\left[h_{Y} / h_{O}\right]$ of the average costs savings for the young, we will end up in scenario V (see Table 7).

${ }^{24}$ Barros (2003). 
Under this procedure, RACPs are based on some sort of acceptable costs rather than the average observed costs in a risk group. ${ }^{25}$ However, this alternative also has some serious drawbacks. In the first place, it requires that average cost savings be known, for example in the case of deductible plans, information must be available on out-of-pocket expenses and moral hazard reduction, as well as in the case of managed care plans, information must be available on the relative cost savings of health plans. Whereas it might be possible to gather information on out-of-pocket expenses, it will be difficult to find valid information on moral hazard reduction and other types of cost saving. Literature broadly reports on the methodological problems of estimating these effects. ${ }^{26}$ Secondly, such a correction is complicated because average cost savings are not static, but result from a dynamic interaction between the premium reduction and the group of consumers choosing that plan. For example, the average cost savings in a deductible plan depends on the risk profile of those choosing a deductible. This risk profile, however, depends on the premium reduction, which again depends on the risk profile and so on.

\section{Conclusion}

An important goal of RACPs to competitive community-rated health plans - that may differ in coverage and/or the organisation of delivering care - is to reduce incentives for risk selection while maintaining incentives for efficiency. In most capitation schemes, RACPs are simply based on the average observed costs in risk groups. This paper has illustrated that under this procedure incentives for efficiency will not always be maintained: when identical risk types concentrate in the same health plans-for example due to selection, specialisation of health plans or just coincidence-cost savings will be (partly) captured by the RACPs and leak away from these plans. As more cost savings are captured by the RACPs, incentives for efficiency diminish. Assuming that the risk portfolios of health plans do not dramatically change from one year to another, this process will also occur when RACPs are based on the average observed costs in a prior year-like in the Dutch capitation scheme-though with some delay.

Our theoretical framework shows that the extent to which cost savings are captured by the RACPs depends on the level at which identical risk types are concentrated in the same health plans and the relationship between risk types and absolute cost savings. In practice, this framework is relevant for both demand-side cost containment and supply-side cost containment. For example, low risks are more likely to be in a deductible plan than high risks. When RACPs are based on the observed costs they will not just compensate for health-related cost differences between low risks and high risks but also for the cost savings in the deductible plan. As a result, health plans are not able to fully incorporate their cost savings into a premium reduction, which makes deductible plans less attractive, probably resulting in hardly any consumer opting for a deductible and hardly any reduction in moral hazard. An example with respect to

\footnotetext{
${ }^{25}$ Schokkaert et al. (2006).

${ }^{26}$ See, for instance, Newhouse (1996b), Gardiol et al. (2006), Grandchamp (2006) and Van Vliet (2004).
} 
514

supply-side cost containment is specialisation of health plans in particular groups of consumers, for example diabetics, residents of a geographical region or the elderly. When health plans attract consumers who are identical in terms of risk adjusters, RACPs will not just compensate for health-related cost differences relative to other risk types, but also for cost savings achieved in these health plans.

These conclusions bring us to some interesting dilemmas. In the first place, improvement of risk adjustment formulas might reduce incentives for risk selection, but might at the same time reduce incentives for efficiency when new risk adjusters reveal concentration of identical risk types in the same health plans. An extreme example: when deductible choice would be included as an explicit risk adjuster, it would compensate for all cost differences between enrollees with a deductible and those without, including the cost savings. As a result, deductible plans can offer no premium reduction compared to alternative plans. In the second place, health plans specialising in specific risk types that are explicitly adjusted for in the risk adjustment formula - for example age, gender, geographical region or a chronic disease - will see a higher percentage of cost savings leaking away as they contract with more of these specific risk types. An extreme example: a health plan covering an entire geographical region will see all cost savings leaking away when that region is included as an explicit risk class in the risk adjustment formula.

\section{References}

Bakker, F.M., Van Vliet, R.C.J.A. and Van de Ven, W.P.M.M. (2000) 'Deductibles in health insurance: Can the actuarially fair premium rebate exceed the deductible?' Health Policy 53(2): 123-141.

Barros, P.P. (2003) 'Cream-skimming, incentives for efficiency and payment system', Journal of Health Economics 22(3): 419-443.

Beck, K. (2004) Risiko Krankenversicherung-Risikomanagement in einem regulierten Krankenversicherungsmarkt (Risk in Health Insurance-Risk Management in a Regulated Health Insurance Market), Bern: Haupt Verlag.

Beck, K., Spycher, S., Holly, A. and Gardiol, L. (2003) 'Risk adjustment in Switzerland', Health Policy 65(1): 63-74.

Browne, M.J. (1992) 'Evidence of adverse selection in the individual health insurance market', Journal of Risk and Insurance 59(1): 13-33.

Buchmueller, T. (2008) 'Community rating, entry-age rating and adverse selection in private health insurance in Australia', The Geneva Papers on Risk and Insurance - Issues and Practice 33(4): 588-609.

Buchner, F. and Wasem, J. (2003) 'Needs for further improvement: risk adjustment in the German health insurance system', Health Policy 65(1): 21-35.

Eekhoff, J., Jankowski, M. and Zimmermann, A. (2006) 'Risk-adjustment in long-term health insurance contracts in Germany', The Geneva Papers on Risk and Insurance-Issues and Practice 31(4): 692-704.

Enthoven, A.C. (1978) 'Consumer-choice health plan - a national-health-insurance proposal based on regulated competition in the private sector', New England Journal of Medicine 298: 709-720.

Gardiol, L., Geoffard, P-Y. and Grandchamp, C. (2006) 'Selection and incentive effects: An econometric study of swiss health-insurance claims data', in P.-A. Chiappori and C. Gollier (eds.) Competitive Failures in Insurance Markets - Theory and Policy Implications, Cambridge: MIT Press, pp. 81-95.

Glazer, J. and McGuire, T.G. (2000) 'Optimal risk adjustment in markets with adverse selection: An application to managed care', American Economic Review 90(4): 1055-1071.

Grandchamp, C. (2006) Self-Selection and Risk Selection on the Swiss Health Insurance Market, University of Lausanne.

Jack, W. (2006) 'Optimal risk adjustment with adverse selection and spatial competition', Journal of Health Economics 25: 908-926. 
Lamers, L.M. 1998 'Risk-adjusted capitation payments: developing a diagnostic cost groups classification for the Dutch situation', Health Policy 45(1): 15-32.

Lamers, L.M. 1999 'Pharmacy costs groups: A risk-adjuster for capitation payments based on the use of prescribed drugs', Medical Care 37(8): 824-830.

Lamers, L.M., Van Vliet, R.C.J.A. and Van de Ven, W.P.M.M. (2003) 'Risk adjusted premium subsidies and risk sharing: Key elements of the competitive sickness fund market in the Netherlands', Health Policy 65: 49-62.

Newhouse, J.P. (1996a) 'Reimbursing health plans and health providers: Efficiency in production versus selection', Journal of Economic Literature 34(3): 1236-1263.

Newhouse, J.P. (1996b) 'Policy watch: Medicare', Journal of Economic Perspectives 10(3): 159-167.

Schellhorn, M. (2001) 'The effect of variable health insurance deductibles on the demand for physician visits', Health Economics 10(5): 441-456.

Schokkaert, E., Beck, K., Shmueli, A., Van de Ven, W.P.M.M., Van de Voorde, C. and Wasem, J. (2006) 'Acceptable costs and risk adjustment: Policy choices and ethical trade-offs', Mimeo.

Schokkaert, E., Dhaene, G. and Van de Voorde, C. (1998) 'Risk adjustment and the trade-off between efficiency and risk selection: An application of the theory of fair compensation', Health Economics 7(5): 465-480.

Schokkaert, E. and Van de Voorde, C. (2004) 'Risk selection and the specification of the conventional risk adjustment formula', Journal of Health Economics 23(6): 1237-1259.

Van de Ven, W.P.M.M., Beck, K., Buchner, F., Chernichovsky, D., Gardiol, L., Holly, A., Lamers, L.M., Schokkaert, E., Shmueli, A., Spycher, S., Van de Voorde, C., Van Vliet, R.C.J.A., Wasem, J. and Zmora, I. (2003) 'Risk adjustment and risk selection on the health insurer market in five European countries', Health Policy 65: 75-98.

Van de Ven, W.P.M.M., Beck, K., Van de Voorde, C., Wasem, J. and Zmora, I. (2007) 'Risk adjustment and risk selection in Europe: 6 years later', Health Policy 83(2): 162-179.

Van de Ven, W.P.M.M. and Ellis, R.P. (2000) 'Risk adjustment in competitive health insurance markets', in A.J. Culyer and J.P. Newhouse (eds.) Handbook of Health Economics, Amsterdam: Elsevier, pp. $755-845$.

Van de Ven, W.P.M.M. and Van Vliet, R.C.J.A. (1994) 'Consumer information surplus and adverse selection in competitive health insurance markets: an empirical study', Journal of Health Economics 14(2): 149-169.

Van Kleef, R.C., Beck, K., Van de Ven, W.P.M.M. and Van Vliet, R.C.J.A. (2008) 'Risk equalization and voluntary deductibles: A complex interaction', Journal of Health Economics 27(2): 427-443.

Van Vliet, R.C.J.A. (2004) 'Deductibles and health care expenditures: Empirical estimates of price sensitivity based on administrative data', International Journal of Health Care Finance and Economics 4 : 283-305.

\section{About the Authors}

Richard van Kleef works as an Assistant Professor at Erasmus University Rotterdam where he obtained his $\mathrm{PhD}$ in 2009. His focus is on two particular topics in the domain of health insurance: cost sharing and risk adjustment. With respect to the first topic, Richard focuses on the development of new forms of cost sharing, which are more effective in reducing moral hazard and protect high-risk consumers from catastrophic out-of-pocket expenses. With respect to the second topic, his focus is on the evaluation and improvement of capitation formulas.

Konstantin Beck born in 1962, in Zurich, Switzerland. Studied Economics at the University of Zurich (1981-1987); Assistant (1985-1991) of Professor Peter Zweifel. 1991 Dissertation in Economics. 1991-93: Manager of a children's relief centre. Since 1993 at CSS Insurance, Lucerne. Today he is Managing Director, responsible 
516

Actuarian, and since 2007 head of the CSS Institute for empirical health economics. Since 2004: Senior Lecturer at the University of Zurich in health economics. His research topics are risk adjustment, capitation payments, managed competition.

Florian Buchner studied mathematics at the University of Augsburg. He worked several years for a private health insurance company and completed his studies with a Master of Public Health at Munich Ludwig-Maximilians-University and a Doctorate in the field of health economics at the University of Greifswald. He worked in different positions for the Divisional Unit Health at Munich Re. Since 2007, he is Professor of Health Economics at Carinthia University of Applied Sciences. His research interest is in health insurance and risk adjustment. 


\section{Appendix A}

See Table A1.

Table A1 Change in RACPs for 26 age/gender-classes in the Swiss risk adjustment formula of 2008 due to cost savings in the voluntary-deductible plan

\begin{tabular}{|c|c|c|c|}
\hline Class & $\begin{array}{c}R A C P \text { without } \\
\text { cost savings }\end{array}$ & $\begin{array}{l}\text { RACP with } \\
\text { cost savings }\end{array}$ & Difference \\
\hline Men, 31-35 & -1859 & -1926 & -67 \\
\hline Men, 36-40 & -1623 & -1696 & -73 \\
\hline Men, 41-45 & -1431 & -1480 & -49 \\
\hline Men, 46-50 & -1274 & -1312 & -38 \\
\hline Men, 51-55 & -694 & -727 & -33 \\
\hline Men, 56-60 & -217 & -244 & -27 \\
\hline Men, 61-65 & 265 & 248 & -17 \\
\hline Men, 66-70 & 1054 & 1048 & -6 \\
\hline Men, 71-75 & 2019 & 2054 & 35 \\
\hline Men, 76-80 & 2271 & 2327 & 56 \\
\hline Men, 81-85 & 2554 & 2623 & 69 \\
\hline Men, 86-90 & 2247 & 2324 & 77 \\
\hline Men, $90+$ & 1937 & 2003 & 66 \\
\hline Women, 31-35 & -1082 & -1191 & -109 \\
\hline Women, 36-40 & -1192 & -1272 & -80 \\
\hline Women, 41-45 & -1211 & -1246 & -35 \\
\hline Women, 46-50 & -875 & -885 & -10 \\
\hline Women, 51-55 & -524 & -525 & -1 \\
\hline Women, 56-60 & 9 & 27 & 18 \\
\hline Women, 61-65 & 379 & 413 & 34 \\
\hline Women, 66-70 & 906 & 969 & 63 \\
\hline Women, 71-75 & 1644 & 1733 & 89 \\
\hline Women, 76-80 & 2125 & 2229 & 104 \\
\hline Women, 81-85 & 2402 & 2518 & 116 \\
\hline Women, 86-90 & 2599 & 2711 & 112 \\
\hline Women, $90+$ & 1955 & 2091 & 136 \\
\hline
\end{tabular}




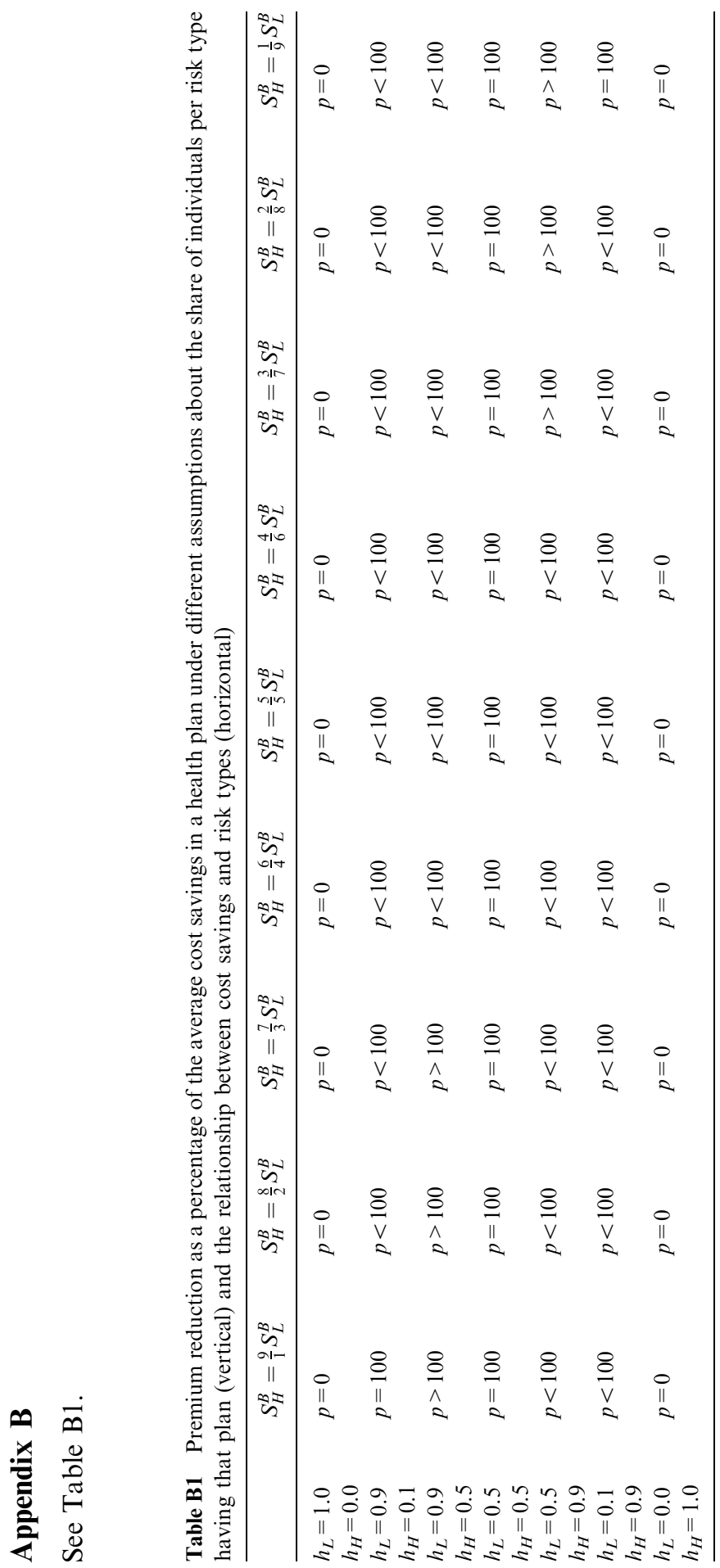




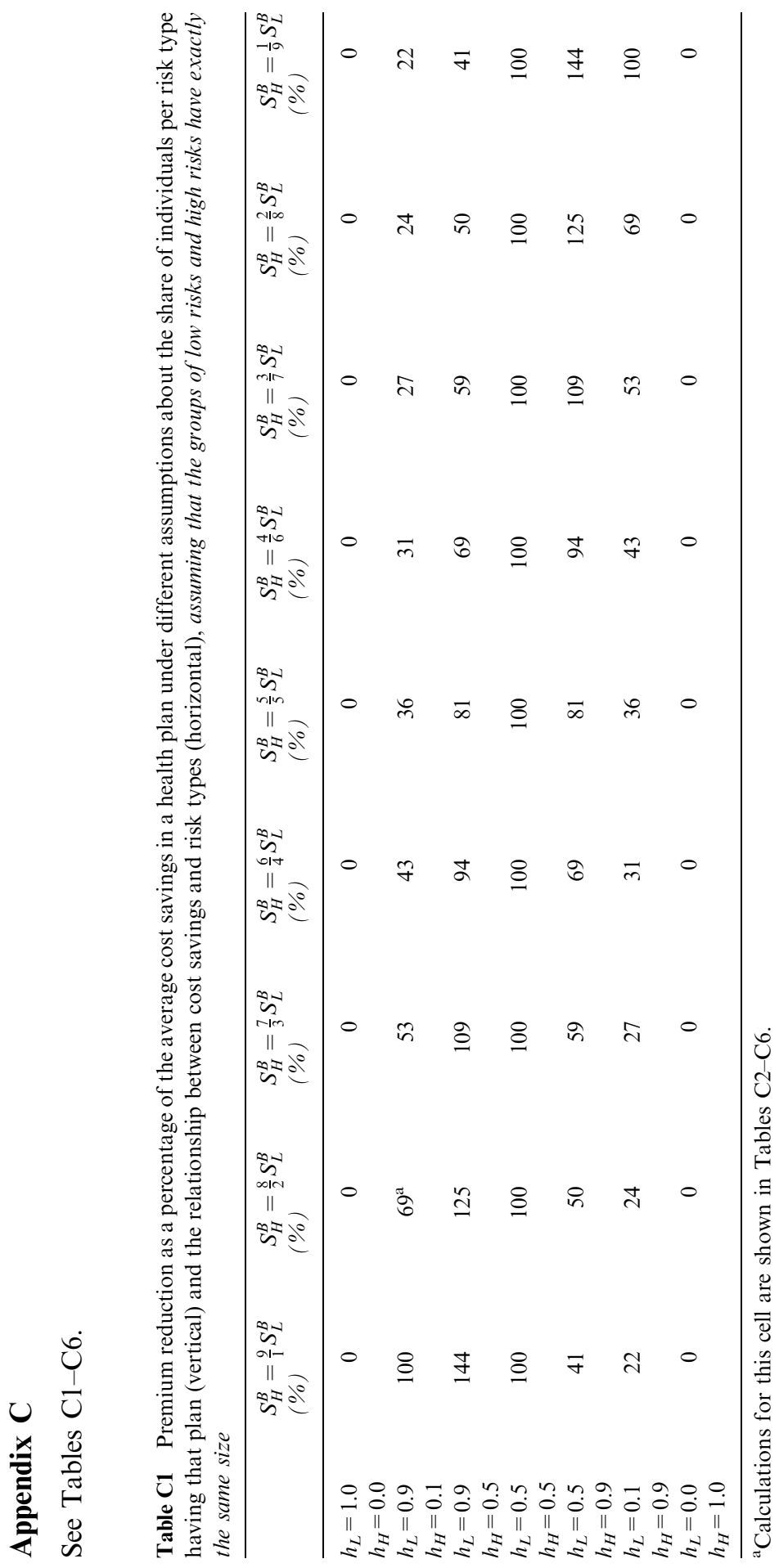


Table C2 Distribution of individuals over health plans and risk types

\begin{tabular}{lccc}
\hline & Plan $A$ & Plan B & Total \\
\hline Low risks & 0.1 & 0.9 & 1 \\
High risks & 0.9 & 0.1 & 1 \\
Total & 1 & 1 & 2 \\
\hline
\end{tabular}

Table C3 Absolute average cost savings

\begin{tabular}{lcc}
\hline & Plan $A$ & Plan B \\
\hline Low risks & 0 & 2 \\
High risks & 0 & 8 \\
Total & 0 & 2.6 \\
\hline
\end{tabular}

Table C4 Absolute effect of cost savings on the average costs

\begin{tabular}{lccr}
\hline & Plan $A$ & Plan B & Total \\
\hline Young & 0 & -2 & -1.8 \\
Old & 0 & -8 & -0.8 \\
Total & 0 & -2.6 & -1.3 \\
\hline
\end{tabular}

Table C5 Absolute effect of cost savings on RACPs

\begin{tabular}{lllr}
\hline & $\begin{array}{l}\text { RACP without } \\
\text { cost savings }\end{array}$ & $\begin{array}{l}\text { RACP with } \\
\text { cost savings }\end{array}$ & Change in RACP \\
\hline Low risks & $C_{L}-C$ & $\left(C_{L}-1.8\right)-(C-1.3)$ & -0.5 \\
High risks & $C_{H}-C$ & $\left(C_{H}-0.8\right)-(C-1.3)$ & 0.5 \\
\hline
\end{tabular}

Table C6 Absolute net effect of cost savings on the total costs and community-rated premiums

\begin{tabular}{lrr}
\hline & Plan A & Plan B \\
\hline Low risks & 0.50 & -1.50 \\
High risks & -0.50 & -8.50 \\
Community-rated premium $^{\mathrm{a}}$ & -0.40 & -2.20 \\
\hline
\end{tabular}

${ }^{\mathrm{a}}$ Thus, the premium reduction of plan B (compared to plan A) equals $69 \%$ of the average cost savings in plan $\mathrm{B}$, that is $(-0.4 \times 1-(-2.2) \times 1) / 2.6=69 \%$. 